\title{
Mean age of stratospheric air derived from AirCore observations
}

\author{
Andreas Engel ${ }^{1}$, Harald Bönisch ${ }^{1, a}$, Markus Ullrich ${ }^{1}$, Robert Sitals ${ }^{1}$, Olivier Membrive ${ }^{2}$, Francois Danis ${ }^{2}$, and \\ Cyril Crevoisier $^{2}$ \\ ${ }^{1}$ Institute for Atmospheric and Environmental Science, Goethe University Frankfurt, Frankfurt, Germany \\ ${ }^{2}$ Laboratoire de Météorologie Dynamique (LMD/IPSL), CNRS, Ecole polytechnique, Université Paris-Saclay, \\ Palaiseau, France \\ anow at: Karlsruhe Institute of Technology, KIT, Karlsruhe, Germany
}

Correspondence to: Andreas Engel (an.engel@iau.uni-frankfurt.de)

Received: 3 February 2017 - Discussion started: 8 February 2017

Revised: 28 April 2017 - Accepted: 5 May 2017 - Published: 12 June 2017

\begin{abstract}
Mean age of stratospheric air can be derived from observations of sufficiently long-lived trace gases with approximately linear trends in the troposphere. Mean age can serve as a tracer to investigate stratospheric transport and long-term changes in the strength of the overturning BrewerDobson circulation of the stratosphere. For this purpose, a low-cost method is required in order to allow for regular observations up to altitudes of about $30 \mathrm{~km}$. Despite the desired low costs, high precision and accuracy are required in order to determine mean age. We present balloonborne AirCore observations from two midlatitude sites: Timmins in Ontario/Canada and Lindenberg in Germany. During the Timmins campaign, five AirCores sampled air in parallel with a large stratospheric balloon and were analysed for $\mathrm{CO}_{2}, \mathrm{CH}_{4}$ and partly $\mathrm{CO}$. We show that there is good agreement between the different AirCores (better than $0.1 \%$ ), especially when vertical gradients are small. The measurements from Lindenberg were performed using small low-cost balloons and yielded very comparable results. We have used the observations to extend our long-term data set of mean age observations at Northern Hemisphere midlatitudes. The time series now covers more than 40 years and shows a small, statistically non-significant positive trend of $0.15 \pm 0.18$ years decade ${ }^{-1}$. This trend is slightly smaller than the previous estimate of $0.24 \pm 0.22$ years decade ${ }^{-1}$ which was based on observations up to the year 2006. These observations are still in contrast to strong negative trends of mean age as derived from some model calculations.
\end{abstract}

\section{Introduction}

Mean age of stratospheric air is the average time it takes for the atmosphere to transport air from the tropospheric source region to a given place in the stratosphere. The concept of mean age was first developed by Kida (1983) and has since been refined and discussed in several high-quality reviews (Hall and Plumb, 1994; Waugh and Hall, 2002). In brief, the concept divides an air parcel into irreducible fluid elements which are irreversibly mixed during transport in the stratosphere. Each such fluid element has a separate transport time and transport path associated with it. The distribution of the statistical probability associated to the different transit times is called the age spectrum and represents a probability density function (pdf) for individual transit times to this air parcel. The first moment of the age spectrum is called the mean age of air. While the age spectrum cannot be measured, mean age can be derived from observations of inert trace gases under certain conditions. In the case of an inert tracer with a perfectly linear trend in the atmosphere, the time lag between the occurrence of a given mixing ratio of a tracer in the troposphere and the occurrence of the same mixing ratio at some place in the stratosphere would be the mean age of air. The two tracers which have been used most widely for this purpose are $\mathrm{CO}_{2}$ and $\mathrm{SF}_{6}$. Neither of these gases increases completely linearly with time, so the shape of the age spectrum needs to be taken into account in deriving mean age.

Mean age has been identified as a valuable tracer to investigate stratospheric transport timescales, for example, by comparing model-derived mean age with observations. Long-term trends in mean age have been used to investigate 
long-term changes in the overall overturning circulation of the stratosphere (Brewer-Dobson circulation, BDC). An increase in the strength of the BDC is expected from model calculation with increasing greenhouse gas concentrations (Austin and Li, 2006; Butchart et al., 2006; Butchart, 2014). This is reflected in overall shorter transit times, thus also lower mean age values in the models.

The experimental database of mean age observations for the verification of such changes is sparse. It relies mainly on very sporadic balloon-borne observations of $\mathrm{CO}_{2}$ and $\mathrm{SF}_{6}$ dating back to 1975 (Engel et al., 2009) and on satellite observations of $\mathrm{SF}_{6}$ (Stiller et al., 2012; Haenel et al., 2015). The balloon-borne observations used in Engel et al. (2009) were taken in a region between 24 and $35 \mathrm{~km}$ where the vertical gradient in mean age at Northern Hemisphere midlatitudes was found to be very small, leading to little variability in this region. The balloon data were limited to a total of 28 flights and showed a positive trend of 0.24 years per decade for this region, which was, however, estimated to be non-significant. Satellite observations of $\mathrm{SF}_{6}$ used in Stiller et al. (2012) and Haenel et al. (2015) were limited to the lifetime of the Envisat satellite of about 10 years. They show an uneven distribution of trends with positive trends in the middle stratosphere of the Northern Hemisphere but negative trends in the Southern Hemisphere. Modelling work by Garny et al. (2014) showed that mixing has a strong influence on mean age and that enhanced mixing leads to higher mean ages in large parts of the stratosphere (aging by mixing). Ploeger et al. (2015) then showed that trends in mean age are to a large degree also influenced by trends in mixing and not only in residual transport. Overall, it has become clear that the interpretation of changes in mean age as changes in residual circulation is inadequate, and that it rather represents a combination of changes in mixing and in residual transport.

The experimental investigation of changes in mean age of stratospheric air is to a large degree restricted by the availability of observations. The balloon-borne data set presented in Engel et al. (2009) relies to a large part on samples collected in the stratosphere using large and heavy cryogenic whole air samplers. These instruments require large and expensive balloons to carry them to altitudes above $25 \mathrm{~km}$. The use of these large balloons involves a large operational team and is very expensive. The uncontrolled parachute descent of such large payloads after the flights further presents a large operational constraint due to safety regulations. These safety regulations make it virtually impossible to fly such large payloads in densely populated areas as central Europe. Due to these operational constraints and in order to create a larger and more representative database, an easy to launch and cheap technique to allow for the measurement of age tracers would be required. AirCore, a new technique for sampling air, which has been suggested by Karion et al. (2010), may provide such an opportunity. In brief, this technique relies on collecting air in a previously evacuated, long stainless steel tube. When deploying AirCore on a balloon, the tube, which is open on one side and closed on the other side, is filled with a fill gas (FG) which has different chemical characteristics from the ambient air that is being sampled. The tube is emptied during the ascent of the balloon due to the decreasing pressure with altitude. Upon descent of the balloon, ambient air is pushed into the AirCore. Due to the length of the tube and the laminar flow during the collection, the air is only partially mixed and the information on the vertical distribution is retained for a while before eventually being mixed due to molecular diffusion. After collection, the sampled air can then be analysed by pushing it out of the tube with a push gas (PG), which must again be well distinguishable from ambient air.

A very lightweight AirCore developed at the University of Frankfurt for deployment on small, cheap and easy to launch balloons used for launching, for example, ozone sondes is presented in Sect. 2 together with the analytical set-up for measurements of the AirCore and the data retrieval. In Sect. 3 we present observations from two midlatitude campaigns: the first is in Timmins, Ontario in 2015 and the second is in Lindenberg, Germany in 2016. Results from a first test campaign in Timmins, Ontario in 2014 have been published in Membrive et al. (2016). Due to technical problems the results from the campaign in 2014 cannot be used to derive mean age. The mean ages calculated from the observations in 2015 and 2016 are presented in Sect. 4 together with an updated long-term evolution of mean age. A summary and conclusions are given in Sect. 5.

\section{University of Frankfurt AirCore}

The AirCore used by University of Frankfurt was developed under two main aspects. The first aspect is that the instrument should be sufficiently light to allow for flights under simple balloons at midlatitudes in Europe. The second aspect is that the AirCore should be optimised to allow measurements at high altitudes with an optimal resolution. The AirCore is currently used for measurements of $\mathrm{CO}_{2}, \mathrm{CH}_{4}$ and $\mathrm{CO}$.

\subsection{Overall concept}

As explained above, the University of Frankfurt AirCore is designed to provide optimum resolution in the stratosphere while keeping the weight sufficiently low for use under a small balloon. The vertical resolution, which can be achieved by AirCore measurements, will generally depend on the geometry of the AirCore itself, on the effective volume of the analyser deployed and on the storage time between collection of the sample and the analysis. The target of our AirCore is to derive the mean age from $\mathrm{CO}_{2}$. As the loss of $\mathrm{CH}_{4}$ in the stratosphere results in the production of $\mathrm{CO}_{2}, \mathrm{CH}_{4}$ needs to be measured simultaneously. We therefore decided to use a Picarro G2401 analyser for this, which is able to measure $\mathrm{CO}_{2}, \mathrm{CH}_{4}, \mathrm{CO}$ and $\mathrm{H}_{2} \mathrm{O}$ with a temporal resolution of about 
$2-3 \mathrm{~s}$ and very high precision, which is better than $0.01 \%$ for $\mathrm{CO}_{2}$ and $0.05 \%$ for $\mathrm{CH}_{4}$ over a $5 \mathrm{~s}$ period under typical ambient conditions. Typical reproducibilities observed during field operations showed precisions of $0.025 \mathrm{ppm}$ of $\mathrm{CO}_{2}$ and $0.2 \mathrm{ppb}$ of $\mathrm{CH}_{4}$. For $\mathrm{CO}$, which was mainly used to distinguish between ambient air and PG, typical precision was $5 \mathrm{ppb}$.

Molecular diffusion is described by Fick's first law of diffusion, which states that the diffusive flux $J$ is proportional to the concentration gradient $\frac{\partial c}{\partial x}$ and the diffusion constant D.

$J=-D \times \frac{\partial c}{\partial x}$

A given amount of air stored in a short tube with large inner diameter will be stretched out over a much shorter distance than the same amount in a narrow and longer tube. The diffusive flux is thus lower when using a longer and thinner tube. As the amount of sample collected by AirCore is proportional to the ambient pressure, very little air is collected at high altitudes. In order to minimise the loss of vertical resolution with altitude, it is desirable to have long, thin tubes for the storage of stratospheric air. On the other hand, the absolute amount of air collected by the AirCore is limited by the total volume of the tube, which is low for tubing with a small inner diameter. We have therefore decided to construct an AirCore from different diameter tubes in such a way that the high-altitude air is stored in the thin-diameter tubing part of the AirCore while the overall volume is provided by widerdiameter tubing in which the lower-altitude air will eventually be stored. The AirCore operated at the University of Frankfurt is thus composed of $20 \mathrm{~m}$ of $8 \mathrm{~mm}$ O.D. tubing, and $40 \mathrm{~m}$ each of 4 and $2 \mathrm{~mm}$ outer diameter tubing. The thinnestwalled tubing we could identify were $0.2 \mathrm{~mm}$ in thickness for 8 and $4 \mathrm{~mm}$ outer diameter tubes. A $2 \mathrm{~mm}$ outer diameter tube with a $0.12 \mathrm{~mm}$ wall thickness is available. The volume per weight is highest for the large outer diameter tubing. All tubes were custom produced for our AirCores. The tubes are joined by solder and lightweight adaptors. As suggested in Karion et al. (2010), all tubes were silanised prior to soldering them together. The AirCore is closed during flight on the $2 \mathrm{~mm}$ side, while the $8 \mathrm{~mm}$ O.D. tube is the open ended. The calculated weight of the AirCore based on the specifications of the tubes is $1.4 \mathrm{~kg}$ for the $100 \mathrm{~m}$-long tube. The final weight of the tube was, however, slightly higher due to the wall thickness being on the high side of the specified tolerance. An automated closure valve (Chen et al., 2017) is added onto the closed side and a sample dryer is mounted on the open end. The drier is based on $\mathrm{Mg}\left(\mathrm{ClO}_{4}\right)_{2}$ filled in a $1 / 2^{\prime \prime}$ O.D. tube of $50 \mathrm{~mm}$ in length, containing a total of $4 \mathrm{~cm}^{3}$ of $\mathrm{Mg}\left(\mathrm{ClO}_{4}\right)_{2}$. The AirCore is mounted in a Styrofoam box for thermal insulation and mechanical protection. As the temperature of the AirCore during collection determines the amount of air which can be sampled, we monitor this temperature with a minimum of three temperature sensors. The automatic closure valve (Chen et al., 2017) closes the AirCore after landing. This valve is controlled by a lightweight electronics package which also includes the data logger for the temperature sensors and was developed at the University of Groningen (Chen et al., 2017). The overall weight of the AirCore in flight mode and using the University of Groningen electronics package and closure valve is about $2.5 \mathrm{~kg}$ including protective housing.

\subsection{Estimated vertical resolution}

The vertical resolution of the derived mixing ratio profiles is influenced by sampling, storing and measurement procedures. The principal procedure to estimate vertical resolution has been outlined by Karion et al. (2010). Resolution is lost due to molecular diffusion during the storage of the sampled air in the AirCore and due to mixing during the sampling and analysis process. Molecular diffusion can be calculated using Fick's law. The mixing process is essentially influenced by two parameters: (i) Taylor dispersion during the collection and analysis of the samples and (ii) the effective cell volume of the analyser, which has to be flushed. Mixing processes are species independent, while the first effect (molecular diffusion during storage) is species dependent, each species having a different molecular diffusion coefficient. The cell volume of the analyser is not an intrinsic limitation of the resolution of the AirCore itself, but will be included in the derived resolution based on the Picarro G2401 analyser used for our analysis. As molecular diffusion is a function of time and molecule, the resolution of our AirCore is also a function of time and will deteriorate with time and differ for each molecule. As explained above, molecular diffusion will lead to a larger loss of resolution in a wider tube. Therefore, our AirCore loses resolution much faster at lower altitudes during storage, where the sampled air is in the wider tube. We have applied the same parameters as described in Karion et al. (2010) to derive the vertical resolution for our AirCore. Figure 1 compares the vertical resolution of our AirCore to other AirCore systems (Karion et al., 2010; Membrive et al., 2016). The calculation is based on the assumption of sampling air down to $1000 \mathrm{hPa}$. At the upper altitudes, the resolution is dominated in this calculation by the effective volume of the analyser cell, while molecular diffusion is the dominant term at low altitudes. The overall vertical resolution of the measurements is better than $1 \mathrm{~km}$ below $24 \mathrm{~km}$ in altitude and increases to about $2.5 \mathrm{~km}$ at $30 \mathrm{~km}$ (Fig. 1). For comparison, the HR-AirCore described by Membrive et al. (2016) achieves a vertical resolution which is better than $300 \mathrm{~m}$ below $15 \mathrm{~km}$ and better than $500 \mathrm{~m}$ below $22 \mathrm{~km}$. However, using much longer tubing results in a higher weight. 


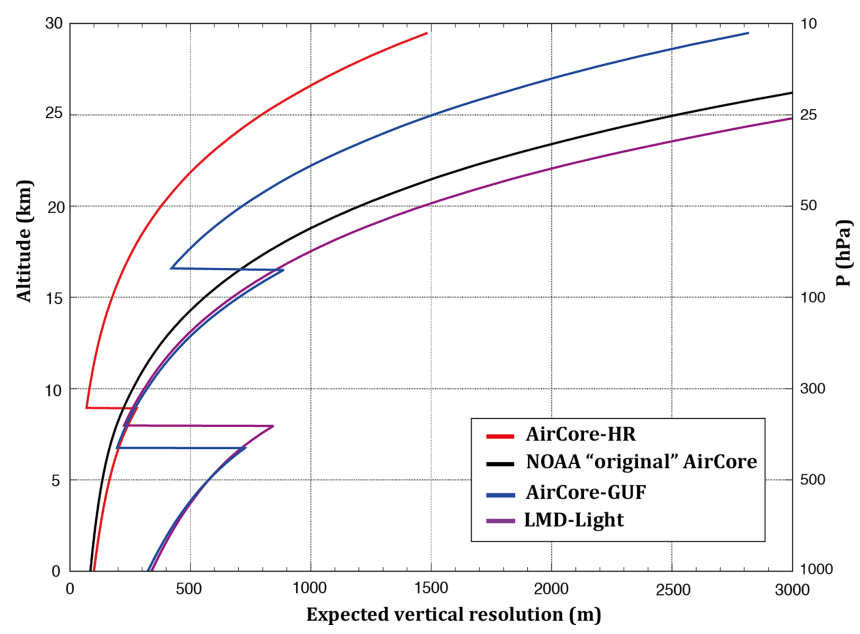

Figure 1. Calculated vertical resolution for $\mathrm{CO}_{2}$ with the Goethe University Frankfurt (GUF) AirCore (AirCore-GUF) in comparison to other AirCores (see text for description), assuming a delay of $3 \mathrm{~h}$ between collection and sampling, a measurement flow of $40 \mathrm{~mL} \mathrm{~min}^{-1}$ and an effective cell volume of $6 \mathrm{~mL}$. The AirCoreHR and LMD-Light AirCores are operated by LMD, while the original NOAA AirCore refers to the AirCore described by Karion et al. (2010).

\subsection{Operation and analytical set-up}

Before the flight the AirCore is checked for leak tightness and cleanliness. As a first test, a gas of known concentration is measured either directly or by passing it through the AirCore and the measurements are compared. As a further test, the AirCore is filled with a gas of known concentration and analysed again after a storage time of $24 \mathrm{~h}$. Only if the $\mathrm{CO}_{2}$ and $\mathrm{CH}_{4}$ readings from both values agree within the uncertainties, the AirCore is considered as clean and leak tight. It is then filled with a fill gas (FG) of known $\mathrm{CO}_{2}, \mathrm{CH}_{4}$ and $\mathrm{CO}$ concentration up to $24 \mathrm{~h}$ before flight. Before flight the automatic valve mounted on the inlet side of the AirCore is opened.

The AirCore should be analysed as quickly after the flight as possible as molecular diffusion decreases the achievable vertical resolution. During the flight in Timmins, Ontario, this occurred about $4 \mathrm{~h}$ after the $\sim 300 \mathrm{~km}$ flight, while the analysis started within an hour after landing during the flights launched from Lindenberg. In order to achieve this fast analysis, the analytical set-up consisting of a Picarro analyser and a gas control system must be deployed in the field. For this purpose, we mounted the analytical system in a car when operating from Timmins and inside our laboratory bus during flights from Lindenberg. The set-up also included a batteryoperated inverter allowing us to run the Picarro for up to $6 \mathrm{~h}$, which also allowed the instrument to remain heated and under constant flow while driving to the predicted landing area. We use the same gas as fill gas (FG) and push gas (PG). This gas mixture contains typical atmospheric $\mathrm{CO}_{2}$ values, typi- cal $\mathrm{CH}_{4}$ values expected around $30 \mathrm{~km}$ in altitude and significantly higher $\mathrm{CO}$ values than observed either in the troposphere or in the stratosphere. Based on the $\mathrm{CO}$ values, it is thus possible to distinguish between the sampled atmospheric air, the PG and the FG, which is left in the tube.

The gas flow system used for the analysis of AirCore is shown in Fig. 2. This system allows the two lines, which are needed to connect the AirCore for the analysis, to be flushed with a standard gas (Cal Gas) or the push gas used for the analysis (connection and flushing, upper panel in Fig. 2). During the connection all dead volumes of the connectors can be flushed, minimising the contamination from ambient air and the Picarro is flushed with push gas. The pressure of the PG is regulated to slightly above ambient pressure (typically $1030 \mathrm{hPa}$ ) and the flow through the Picarro is regulated to $40 \mathrm{~mL} \mathrm{~min}^{-1}$. Once all lines are flushed and connected and the Picarro gives a stable reading of the expected value for the PG, the two-position valve can be switched. PG regulated at $1030 \mathrm{hPa}$ is then flushed through the AirCore with a flow of $40 \mathrm{~mL} \mathrm{~min}^{-1}$. The stratospheric (upper altitude) air is flushed out first. Before stratospheric air arrives at the Picarro analyser, the standard gas that was used for flushing the connection lines will arrive first, followed by the remaining FG from the AirCore. The amount of FG left will depend on the lowest pressure reached during flight and on the temperature of the AirCore during that phase (see section data retrieval). Fig. 3 shows a typical example of the raw analytical results from the measurements of two AirCores that embarked simultaneously on board the flight from Timmins in 2015 (see Sect. 3.1). Figure 4 shows a zoomed-in image on the $\mathrm{CO}$ measurements shortly after switching the rotary valve. The PG with its high $\mathrm{CO}$ values close to $1.4 \mathrm{ppm}$ is measured. Then the $\mathrm{CO}$ values drop due to the lower values of the calibration gas with which the connection line was flushed. This is then followed by the FG remaining in the tube. Note that during this flight the amount of FG left was not sufficient for the Picarro to arrive at its expected value of close to $1.4 \mathrm{ppm}$. After passing the peak with high $\mathrm{CO}$ from the FG, the values drop sharply, showing much lower CO values. These lower $\mathrm{CO}$ values are expected in the middle stratosphere (Toon et al., 1999; Engel et al., 2006b) due to the photochemical balance between the production of $\mathrm{CO}$ from oxidation of $\mathrm{CH}_{4}$ and the breakdown of $\mathrm{CO}$ due to oxidation with the $\mathrm{OH}$ radical. The transition from high CO (remaining FG) to low CO thus marks the beginning of the sampled air at the upper part of the profile. In a similar way, the transition from rather low tropospheric $\mathrm{CO}$ to high $\mathrm{CO}$ marks the time at which all the sampled air has been pushed out of the AirCore and the PG used to push the air out of the AirCore is seen by the analyser.

\subsection{Data retrieval}

The Picarro analyser will deliver a time series of mixing ratios as a function of measurement time. The absolute values of the Picarro analyser are transferred to the WMO scale 
(a)

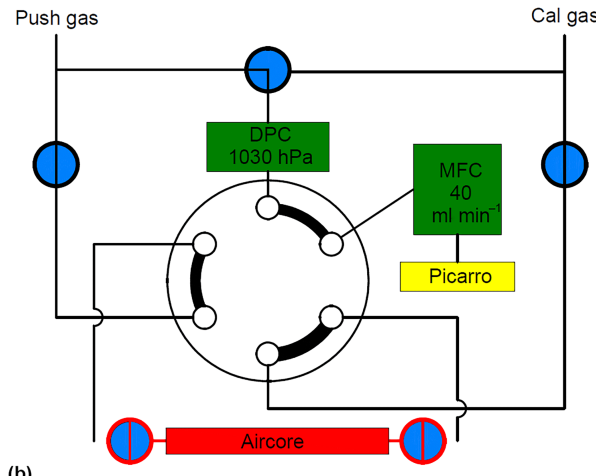

(b)

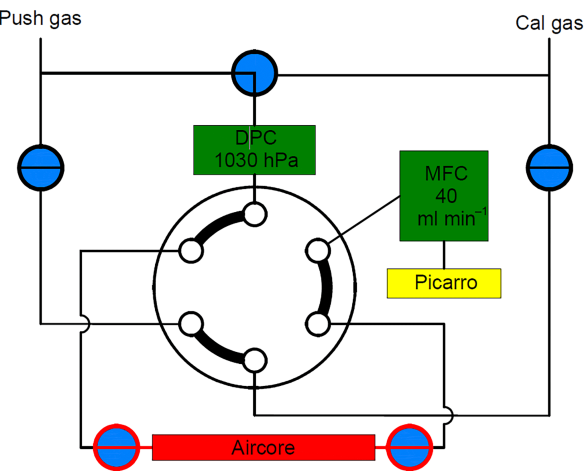

Figure 2. Analytical set-up for the measurement of AirCore. The AirCore including the valves which are flown is shown in red. In the bypass/flushing position (a) the push gas (PG) is measured bypassing the AirCore. The transfer lines to the AirCore can be flushed with PG or with a calibration standard (Cal Gas), allowing us to connect the AirCore to the analytical system without contamination. For the analysis the transfer lines to the AirCore are closed, the AirCore valves are opened and the two position valve is switched to the measurements mode (b). The PG is passed through the AirCore and pushes the air to the Picarro. Pressure and flow are controlled allowing for a very constant air flow.

(X2007 scale for $\mathrm{CO}_{2}$ and X2004a scale for $\mathrm{CH}_{4}$ ) based on a calibration function derived from absolute values of four gas bottles with a range of $\mathrm{CO}_{2}$ values between 390 and $416 \mathrm{ppm}$ of $\mathrm{CO}_{2}$ and 1.07 to $1.91 \mathrm{ppm}$ of $\mathrm{CH}_{4}$ (only three gas bottles). The mixing ratios determined by the Picarro analyser have to be matched to the altitude at which the air was sampled by the AirCore during the flight. The basis of this altitude attribution is the ideal gas law and the molar amount sampled at each altitude during the flight. This matching is achieved in a four-stage process. (i) The amount of remaining fill gas is determined, (ii) the sampling of air based on the ideal gas law is calculated. (iii) The start and end times of AirCore in the analyser time series are determined and finally (iv) the sampling and the analysis can be matched based on the molar amount.

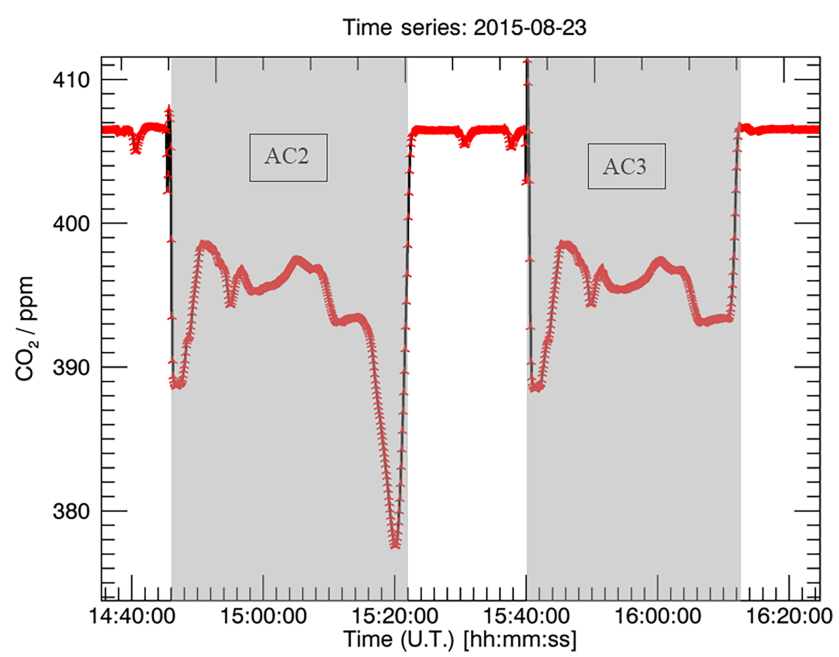

Figure 3. Raw analytical results for $\mathrm{CO}_{2}$ from the measurements of the two AirCores flown from Timmins in 2015. Note that AC2, which was measured first, contained a closure valve, while AC 3 was left open until the recovery team was able to reach the instrument. The lowest part of the AC3 profile was therefore lost due to the warming of the AirCore on the ground. The grey shaded areas denote the measurements of air from the AirCore. The stratospheric part of the profiles is always measured first. Before the measurements of AC2, between the measurements of the AirCores and after the measurement of AC3, PG is measured by the Picarro analyser.

\subsubsection{Determination of remaining fill gas}

In the case of slow vertical displacement of the balloon, pressure equilibrium between the AirCore and the surrounding air can be assumed. Under this assumption of an instantaneous pressure equilibrium, the molar amount $n$ of an ideal gas stored in volume $V$ at pressure $p$ and temperature $T$ is according to the ideal gas law:

$n=\frac{p \times V}{R \times T}$,

where $\mathrm{R}$ is the general gas constant. The temperature in this aspect is not the ambient temperature but the temperature of the coil, as we assume an instantaneous equilibrium between temperature of the air inside the AirCore with the coil temperature. In the first step the amount of FG remaining in the AirCore at the top of the profile is then calculated by searching for the minimum in $\frac{p}{T}$.

As noted above, the assumptions about pressure equilibrium between air inside the AirCore and outside air needs to be made in this calculation. While this is certainly a valid assumption for slowly descending balloon, it will be less valid with a faster descending balloon. In the case of a rubber balloon, which will burst while still ascending and then immediately start to descend, the situation is even more difficult. The pressure inside the AirCore will actually be higher than the outside pressure during the beginning of the descent, because a non-equilibrium will exist both for the emptying of 
the tube during ascent and the refilling of the tube during the descent. The size of this non-equilibrium effect will depend on the geometry of the AirCore but also on the filling of the sample dryer. In particular, the latter may provide a significant flow restriction if the $\mathrm{Mg}\left(\mathrm{ClO}_{4}\right)_{2}$ is packed very densely. The amount of FG left in the AirCore is thus expected to differ significantly from the equilibrium amount calculated before based on the minimum in $\frac{p}{T}$. We have taken particular care to have a short and loosely packed dryer providing minimal flow restriction. As the FG used in our case differs significantly in $\mathrm{CO}$ values from ambient air, and from the calibration gas used, it is possible to determine the amount of remaining FG by integrating the $\mathrm{CO}$ peak observed during the measurement of the AirCore (Chen et al., 2017), as illustrated in Fig. 4. When switching from the bypass to the measurements mode, the gas inside the Picarro measurement cell is first replaced by the calibration gas, which was used to flush the transfer line to the AirCore during the connection. The calibration gas (Cal Gas) is then replaced by the FG which remained in the AirCore and then by ambient stratospheric air. All of these gases are partially mixed and all of them contain some CO. In order to separate the amount of $\mathrm{CO}$ (due to PG and Cal Gas) from the signal (due to remaining FG) we performed a measurement in a similar set-up but our AirCore was filled with pure nitrogen, which contained no detectable amounts of $\mathrm{CO}$. The $\mathrm{CO}$ in this set-up is thus not due to remaining FG and can be used to correct the offset due to PG and Cal Gas when integrating the $\mathrm{CO}$ peak from the remaining FG. Using the known mixing ratio of $\mathrm{CO}$ in the FG, the molar amount of remaining FG can be determined. In the case of the two fast descent profiles from Lindenberg (see Sect. 3), the pressure of remaining FG was determined to be 17.2 and $7.3 \mathrm{hPa}$, respectively, while the corresponding pressures derived from the minimum in $\frac{p}{T}$ was slightly lower at 15.2 and $7 \mathrm{hPa}$, respectively. The differences are rather small, corresponding to altitude differences of a kilometre or less, as the flow restriction of our AirCore is low due to the large inner diameter of the $8 \mathrm{~mm}$ tube (which carries the largest part of the volume) and the carefully packed sample dryer. In the following we have therefore only corrected this effect by adopting the upper sampling pressure during the Lindenberg flights to the value calculated from the integration of the $\mathrm{CO}$ peak of the remaining FG.

\subsubsection{Sampling of ambient air with AirCore}

In the second step, we determine the amount of moles sampled at each time step of the balloon trajectory. Again in the case of slow descent the assumption of pressure equilibrium between the tube and the sampled ambient air is justified. Starting at the molar amount determined during step 1 and adding up over the pressure and coil temperature measured during the descent of the balloon results in a matrix linking ambient pressure and altitude to the sampled molar amount. In the case of a faster descent, the assumption of

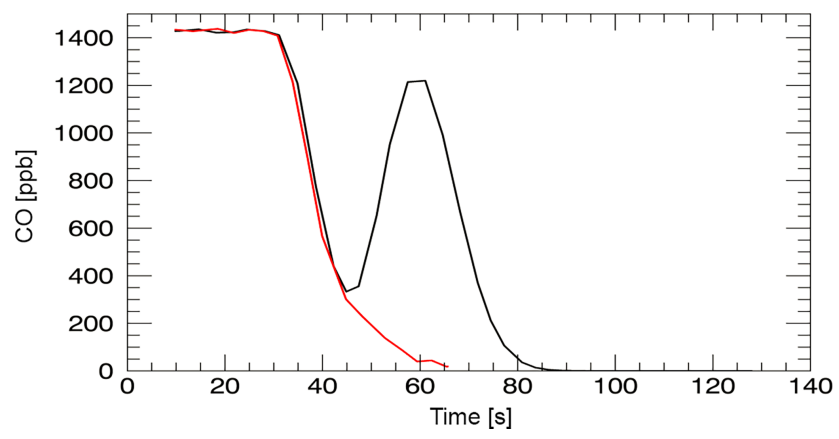

Figure 4. Zoomed in image of $\mathrm{CO}$ measurements from the flight on 25 May 2016. After switching the two position valves to measurement mode. Before switching, the analyser measures the high $\mathrm{CO}$ mixing ratios of the $\mathrm{PG}$, then a decrease in $\mathrm{CO}$ is observed, representing the low $\mathrm{CO}$ values of the $\mathrm{Cal}$ gas used for flushing the transfer lines, and finally the $\mathrm{CO}$ peak from the remaining FG is measured (note that PG and FG are taken from the same gas cylinder and thus have identical mixing ratios). After the remaining PG has passed the analyser, the $\mathrm{CO}$ values drop to the expected lowstratospheric $\mathrm{CO}$ values. The red line shows the $\mathrm{CO}$ values measured using the same set-up but analysing an AirCore filled with $\mathrm{CO}$-free nitrogen. The area between the black $\mathrm{CO}$ peak and the red baseline represents the amount of FG left in the AirCore.

pressure equilibrium is not completely valid, but as shown in Sect. 2.4.1. the effect is small. To a first order this is compensated by starting the summing at the molar amount determined from integration of the $\mathrm{CO}$ peak as described in Sect. 2.4.1.

The approach of summing up the amount of moles in the AirCore during the flight will also take into account that air from the AirCore can be lost again if the pressure of ambient air is below that of the AirCore, e.g. in case the balloon ascends (which can occur for large stratospheric balloons) or if the AirCore heats up after landing without being closed. The procedure is thus integrated in time until the moment that the AirCore is closed either manually or via an automatic closure valve.

\subsubsection{Matching AirCore and Picarro data}

In the third step we determine the start and ends points in the measurements of the air mass sampled and stored in the AirCore with the Picarro (see Fig. 2). This is achieved by fitting a Gaussian curve to the $\mathrm{CO}$ peak from the remaining FG (see Fig. 4). In the case that there is so much FG left that the $\mathrm{CO}$ peak reaches a plateau, the left and right side of the remaining $\mathrm{CO}$ from FG are fitted separately using only one side of the Gaussian for fitting. The time when the peak reaches half its height is chosen as the start time. The time derived for the rising CO peak is then taken as the start time of the FG. The time derived for the descending part of the peak is taken as the start of the AirCore, i.e. ambient stratospheric air. We chose to use this second point as the start point and 
associate it with the amount of remaining FG determined in Sect. 2.4.1. The determination of start and end points of the AirCore analysis in the Picarro time series is critical in correctly assigning the measured mixing ratio to the sampling location and altitude. The start point of the AirCore is an especially critical parameter as an offset of $1 \mathrm{hPa}$ will result in a significant shift in altitude in the stratosphere. The fourth step is then to calculate the molar amount of air passing through the Picarro and link this to the molar amount sampled with the AirCore. The link between the molar amount and the time of measurement is straightforward, as the flow through the Picarro is regulated to be constant (in our case $40 \mathrm{~mL} \mathrm{~min}^{-1}$ ) and temperature and pressure of the measurement cell of the Picarro analyser are also controlled.

\subsubsection{Correction of mixing ratios for mixing between AirCore and fill gas}

In order to keep the effect of mixing between FG and ambient stratospheric air small, the FG had mixing ratios close to those expected in the middle stratosphere. The FG, which is also used as PG, has a mixing ratio of about $407.75 \mathrm{ppm}$ of $\mathrm{CO}_{2}$ and $1228.6 \mathrm{ppb}$ of $\mathrm{CH}_{4}$. On the other hand, the PG has much higher CO (about $1400 \mathrm{ppb}$ ) in order to allow a clear distinction from both tropospheric and stratospheric air. In particular, stratospheric air has much lower $\mathrm{CO}$ mixing ratios, which are on the order of $20 \mathrm{ppb}$ (Engel et al., 2006b; Toon et al., 1999). Our measurements showed a gradual decrease of $\mathrm{CO}$ values from the high FG values to the significantly lower stratospheric mixing ratios. Values as low as $20 \mathrm{ppb}$ were only observed sporadically, with values around $100 \mathrm{hPa}$ pressure altitude typically being in the $30 \mathrm{ppb}$ range. This enhancement could either be caused by $\mathrm{CO}$ production from the reaction of ozone with the tubing or it could be a measurement artefact as the Picarro is not well suited for such low $\mathrm{CO}$ mixing ratios. This gradual decrease from the FG values to stratospheric values is due to a combination of mixing and diffusion. While mixing is similar for all species, molecular diffusion depends on the diffusion coefficient and is different for each gas. The upper part of the profile is stored in the $2 \mathrm{~mm}$ O.D. tube. In this tube molecular diffusion only leads to a very gradual mixing of the two gases (FG and ambient air). Most of the gradient is due to mixing during the analysis (the limiting part is the volume of the analyser cell). Therefore, this gradient can be treated as a gradient caused by mixing and not diffusion, and the mixing should be similar for all species. We will thus use the large difference in $\mathrm{CO}$ to characterise the fraction of $\mathrm{FG}$ in the analysis and correct the observed mixing ratios of $\mathrm{CH}_{4}$ and $\mathrm{CO}_{2}$ for the remaining impact of FG. In order to determine the fraction of remaining FG an assumption must be made on the expected stratospheric mixing ratio of $\mathrm{CO}$. As we expect that the correction should approach zero once the cell has been flushed a few times, we have chosen to use the average $\mathrm{CO}$ value observed between 80 and $100 \mathrm{hPa}$ as the expected value. Using this target value the fraction of FG is calculated from the difference between the measured and the expected $\mathrm{CO}$ mixing ratios and the observed mixing ratio from the Picarro measurements is corrected accordingly.

\section{Atmospheric observations}

The AirCore developed at the University of Frankfurt is sufficiently light to be flown with a small balloon. However, we performed our first test flights using large stratospheric balloons launched by CNES from Timmins in Ontario. Two such test flights were launched in order to compare our results with those of other groups. The first test flights were launched in 2014. The results from the first flight in 2014 is reported by Membrive et al. (2016). Due to a balloon trajectory which was not adapted to AirCore measurements (long ceiling and long float of the balloon around $20 \mathrm{~km}$ in altitude), the profiles obtained for $\mathrm{CO}_{2}$ from AirCore could not be used to derive mean age, as the AirCore showed unrealistically low values of $\mathrm{CO}_{2}$ around the float altitude, possibly due to an interference with the sample dryer (Membrive et al., 2016). These data are therefore not discussed in this paper. During a second flight of the same payload as reported in Membrive et al. (2016), the vertical velocities were much better adapted and we could derive profiles of $\mathrm{CO}_{2}, \mathrm{CO}$ and $\mathrm{CH}_{4}$. These are presented in Sect. 3.1. In Sect. 3.2. we present the first results from our AirCore measurements at midlatitudes using a small and easy to launch rubber balloon similar to those used for ozone soundings.

\subsection{Timmins 2015}

The payload launched from Timmins in the year 2015 was very similar to the one described in Membrive et al. (2016). It consisted of a combination of two AirCores by the University of Frankfurt, one high-resolution AirCore (Membrive et al., 2016) and two lightweight AirCores by the Laboratoire de Meteorologie Dynamique (LMD). In contrast to the Picarro G2401 used by the University of Frankfurt, the LMD team used a G2301 analyser, which lacks the capacity to measure CO. The payload also included two pico-SDLA spectrometers (Ghysels et al., 2014; Durry and Hauchecorne, 2005) for measurements of $\mathrm{CO}_{2}$ and $\mathrm{CH}_{4}$, which are based on in situ infrared absorption measurements. Results from the latter measurements were perturbed due to thermal drifts in laser emission wavelength and are not available at the time of writing. The balloon was launched from Timmins, Ontario, on 22 August 2015 and reached a minimum pressure of about $11 \mathrm{hPa}$. In order to reach a zone where a safe landing was possible, the balloon was left to drift westwards and a slow descent of the balloon was started in the early morning of 23 August (08:30 UT). The payload was separated from the balloon just below $100 \mathrm{hPa}$ pressure and the payload landed at about 10:40 UT. The recovery team was able to recover the 


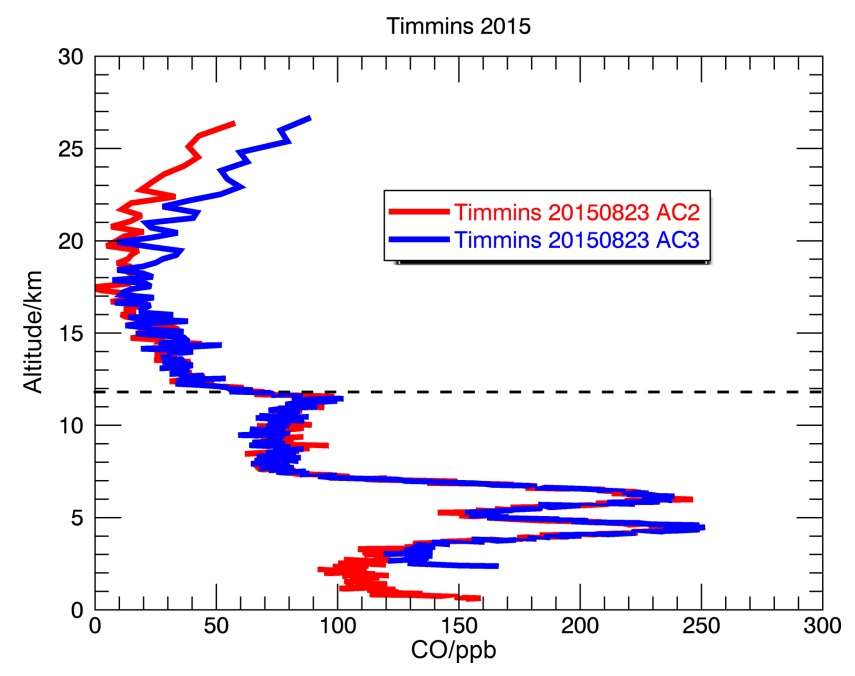

Figure 5. Vertical profiles of $\mathrm{CO}$ derived for the flight on $23 \mathrm{Au}-$ gust 2015 from Timmins, Ontario, Canada. The two peaks with enhanced $\mathrm{CO}$ around $5 \mathrm{~km}$ in altitude are observed in both AirCores and are probably caused by wildfires occurring in Canada during August 2015. There are no CO measurements from the LMD AirCores due to the Picarro analyser used by LMD. The dashed lines represent the thermal tropopause according to the WMO definition.

payload such that the analysis could be started about $4 \mathrm{~h}$ after landing.

Figures 5-7 show the vertical profiles of $\mathrm{CO}, \mathrm{CH}_{4}$ and $\mathrm{CO}_{2}$ as measured with the Picarro analyser for both AirCores by GUF and in comparison to the LMD AirCores (only for $\mathrm{CH}_{4}$ and $\mathrm{CO}_{2}$ ). The altitude attribution is based on the $\mathrm{CO}$ peak as described in Sect. 2.4. One of the AirCores (AC2) was operated with the automatic closure valve and thus did not lose any air while warming up on the ground after landing. The profile from this AirCore extends to the ground, while other profile (AC-3) ends higher up due to the loss of air. First of all, two peaks in CO are observed in the troposphere, which are found at the same altitude for both AirCores. They could have been caused by biomass burning from wildfires occurring over western Canada during the observation period. Lowest values of $\mathrm{CO}$ in the stratosphere are of the order of 10-20 ppb, in agreement with expected steady-state values (Toon et al., 1999; Engel et al., 2006b). AC-3, which was measured after AC-2 shows an increase in $\mathrm{CO}$ mixing ratios above $20 \mathrm{~km}$, which is most probably due to the longer storage time, resulting in more diffusive mixing with remaining fill gas.

Figure 6 shows the vertical profiles of $\mathrm{CH}_{4}$ derived from the five independent AirCores all mounted on the same gondola. A remarkably good agreement is observed, as already shown for observations in 2014 (Membrive et al., 2016). As also discussed in (Membrive et al., 2016) it is obvious that the AirCore-HR is able to capture fine-scale vertical structures which are not present in the profiles derived from the lightweight AirCore of the University of Frankfurt nor from

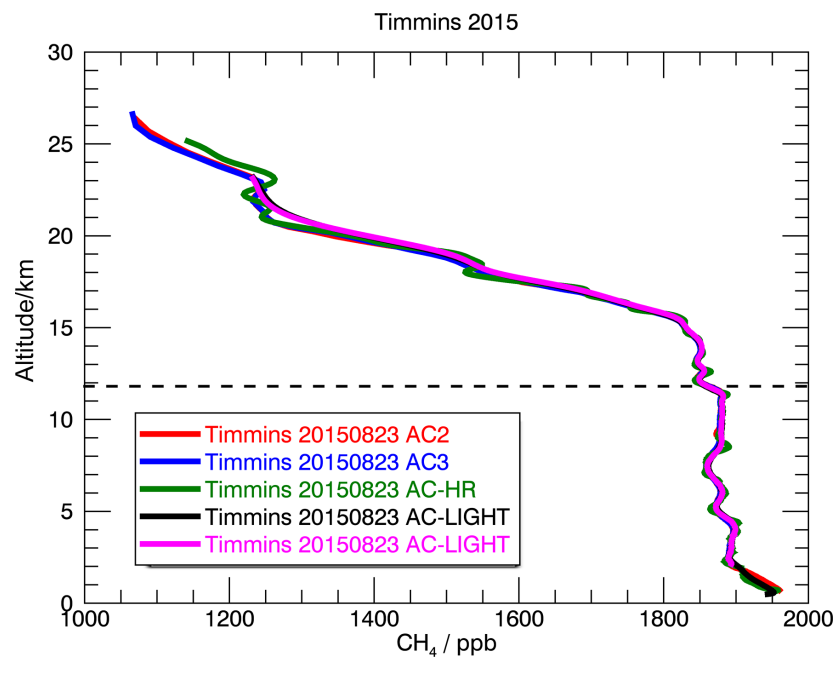

Figure 6. Vertical profiles of $\mathrm{CH}_{4}$ derived for the flight on $23 \mathrm{Au}$ gust 2015 from Timmins, Ontario, Canada. Excellent agreement is observed between all AirCores. There is a slight high bias of the light LMD AirCores above $20 \mathrm{~km}$ with respect to both the University of Frankfurt AirCores (red and blue trace) and the highresolution (HR) AirCore (green trace). The fine structures observed by the HR AirCore are smeared out in the lightweight AirCores by the University of Frankfurt and LMD. The dashed lines represent the thermal tropopause according to the WMO definition.

the lightweight AirCore of LMD, which have a similar vertical resolution in the troposphere but a lower vertical resolution in the stratosphere. The vertical profile of the lightweight LMD AirCore is only derived up to about $23 \mathrm{~km}$ in altitude. Above $19 \mathrm{~km}$ the lightweight LMD AirCore shows some deviations from the high-resolution AirCore and the University of Frankfurt AirCores. The University of Frankfurt AirCore on the other hand is capable of capturing some local structure around $21-22 \mathrm{~km}$ in altitude, although the two local minima from the high-resolution AirCore are smeared out to one broader minimum. Above $23 \mathrm{~km}$ there seems to be a small altitude mismatch between the University of Frankfurt and the high-resolution AirCore, which is, however, less than $1 \mathrm{~km}$. This altitude discrepancy is explained by the uncertainty in matching the Picarro measurements to the AirCore sampling, which is also treated slightly differently in the LMD and the University of Frankfurt retrieval. In order to compare the values of the different AirCores, we binned the data into $1 \mathrm{~km}$ intervals and then calculated averages for each AirCore in these bins. In the troposphere (values between 3 and $13 \mathrm{~km}$ in altitude), the standard deviation between these $1 \mathrm{~km}$ bins is $1.4 \mathrm{ppb}$, or $0.08 \%$. In the stratosphere the deviations are higher due to the large vertical gradient. Absolute deviations are on average (between 15 and $24 \mathrm{~km}$ in altitude) $11 \mathrm{ppb}$ or $0.75 \%$. The agreement of the two University of Frankfurt AirCores is much better $(0.17 \mathrm{ppb}$ or $0.01 \%$ in the troposphere and $3.8 \mathrm{ppb}$ or $0.25 \%$ in the stratosphere), as is that 


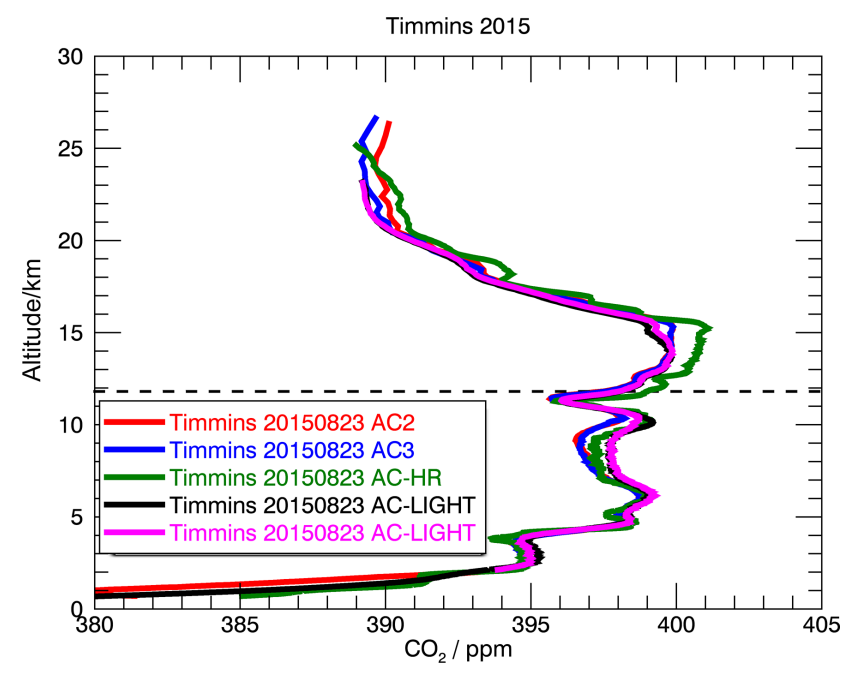

Figure 7. Vertical profiles of $\mathrm{CO}_{2}$ derived for the flight on $23 \mathrm{Au}$ gust 2015 from Timmins, Ontario, Canada. The overall structure is captured very well by all AirCores. Again, a finer structure is obvious in high-resolution AirCore. See text for discussion of the differences between the different AirCores. The dashed lines represent the thermal tropopause according to the WMO definition.

of the two lightweight LMD AirCores $(0.28 \mathrm{ppb}$ or $0.015 \%$ in the troposphere and $1.6 \mathrm{ppb}$ or $0.1 \%$ in the stratosphere).

The $\mathrm{CO}_{2}$ measurements from the five AirCore are compared in Fig. 7. The overall shapes of the profiles from the different AirCores show good agreement. In particular, rather small-scale phenomena are also resolved and observed in all AirCores. For instance the small-scale structure at around $13 \mathrm{~km}$ is observed in all AirCores, again showing that the sampling and altitude attribution give consistent results. As already discussed by Membrive et al. (2016), $\mathrm{CO}_{2}$ measurements seem to show more deviations. However, it should be noticed that the range shown for $\mathrm{CO}_{2}$ is much smaller than for $\mathrm{CH}_{4}$. In contrast to $\mathrm{CH}_{4}$ the deviations in the troposphere and the stratosphere are very similar, as the vertical gradient is similar. In absolute terms, the deviations are typically $0.35 \mathrm{ppm}$ or about $0.09 \%$. This deviation is thus on a very similar level to those observed for $\mathrm{CH}_{4}$ in the troposphere. Overall, this agreement is very good, taking into account that the different AirCores partly use different data retrieval algorithms, have different geometries and thus also have different vertical resolutions. As in the case of $\mathrm{CH}_{4}$, we note that the agreement between the two University of Frankfurt AirCores is much better $(0.04 \mathrm{ppm}$ or $0.01 \%$ in the troposphere and $0.17 \mathrm{ppm}$ or $0.04 \%$ in the stratosphere), as is the agreement between the two lightweight LMD AirCores $(0.05 \mathrm{ppm}$ or $0.015 \%$ in the troposphere and $0.07 \mathrm{ppm}$ or $0.02 \%$ in the stratosphere). This shows that the differences are systematic and must be related to the geometries of the different AirCores and the related uncertainties in the altitude attributions.

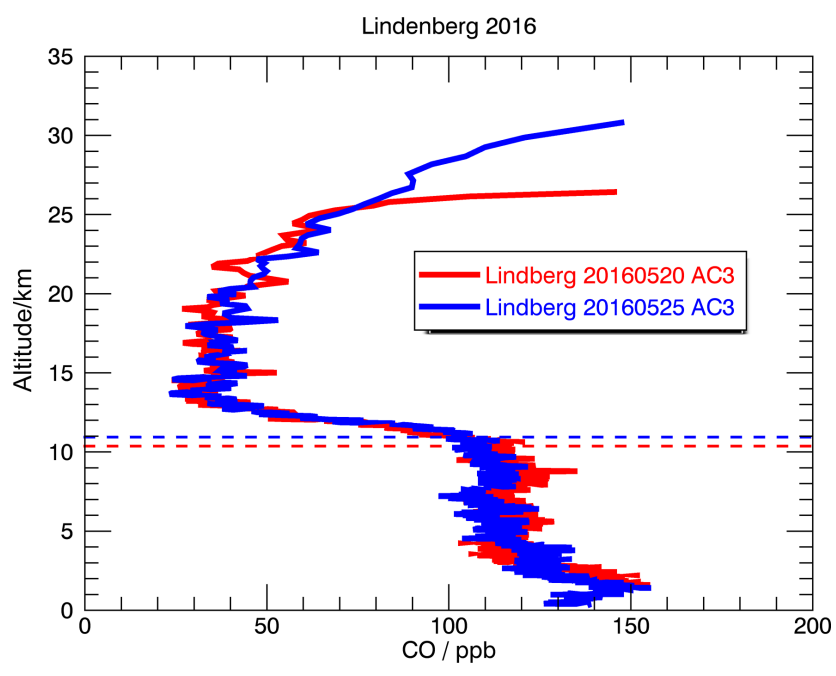

Figure 8. Vertical profiles of $\mathrm{CO}$ derived for the flights on 20 and 25 May 2016 from Lindenberg in Germany. The flight on May 25 reached higher altitudes due to use of a larger balloon. The dashed lines represent the thermal tropopause according to the WMO definition.

\subsection{Lindenberg 2016}

A first test campaign to study the use of our AirCore using small balloons was conducted from the Lindenberg Meteorological Observatory, Germany. AirCores were launched on 20 and 25 May 2016. The balloon used for the first flight was a TA 1500 balloon. A larger balloon (TA 3000) was used for the flight on 25 May, which reached a higher ceiling altitude. Ceiling pressures were 15.2 and $7 \mathrm{hPa}$, respectively. Large parachutes were used in order to slow down the descent speed and minimise the effects due to non-equilibrium of pressure inside and outside the AirCore. For both measurement flights we were able to recover the AirCore very fast and start the analysis within an hour after landing. The retrieval procedure was similar to the one for the flight from Timmins in 2015 with the exception that we derived the pressure at which sampling began not from the measurements of ambient pressure but from the integration of the $\mathrm{CO}$ peak as described in Sect. 2.4.1. (diploma thesis Markus Ullrich, the University of Frankfurt, December 2016).

Figures 8 to 10 show the vertical profiles of $\mathrm{CO}, \mathrm{CH}_{4}$ and $\mathrm{CO}_{2}$ from the two flights conducted in May 2016. For $\mathrm{CO}$ the general agreement between both flights is very good, even though they are 5 days apart. $\mathrm{CO}$ values are higher than observed in Timmins in 2015. This could either be due to the use of a different Picarro analyser (note that these values are close to the detection limits of $\mathrm{CO}$ ) or to enhanced $\mathrm{CO}$ in early spring, e.g. due to descending mesospheric air during the polar winter. For all species there is a distinct change at the tropopause, which is observed around $10.4 \mathrm{~km}$ in altitude on 20 May and $10.9 \mathrm{~km}$ on 25 May. The decrease in tracer mixing ratios, especially for $\mathrm{CO}$, is observed at the same al- 


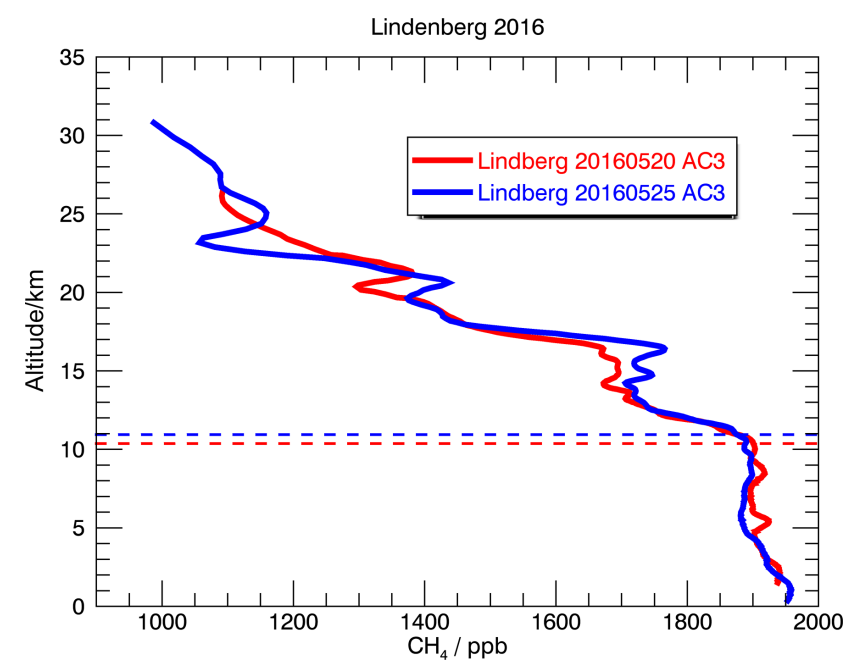

Figure 9. Vertical profiles of $\mathrm{CH}_{4}$ derived for the flights on 20 and 25 May 2016 from Lindenberg in Germany. The flight on 25 May reached higher altitudes due to use of a larger balloon. The dashed lines represent the thermal tropopause according to the WMO definition.

titude as the thermal tropopause, showing that the altitude attribution as explained in Sect. 2 yields realistic results.

For $\mathrm{CH}_{4}$ and $\mathrm{CO}$ this is due to the chemical loss in the stratosphere, whereas $\mathrm{CO}_{2}$ is very long lived in the stratosphere. The decrease in $\mathrm{CO}_{2}$ values above the tropopause is mainly caused by the high values of $\mathrm{CO}_{2}$ in the Northern Hemisphere troposphere during spring, while the air above the tropopause partly entered through the tropical tropopause and partly during late summer of the preceding year when tropospheric $\mathrm{CO}_{2}$ values were lower due to the seasonal cycle (Bönisch et al., 2009). $\mathrm{CH}_{4}$ and $\mathrm{CO}_{2}$ show some fine structures in the stratosphere during both flights. There is a local maximum in $\mathrm{CO}_{2}$ and $\mathrm{CH}_{4}$ at around $21 \mathrm{~km}$ in altitude on 20 May and a similar local maximum is observed on 25 May at about $20.5 \mathrm{~km}$ in altitude. The maxima and minima in $\mathrm{CO}_{2}$ and $\mathrm{CH}_{4}$ are collocated at the same altitude. Therefore, this is clearly a dynamical feature where $\mathrm{CO}_{2}$-rich (younger) air (see Sect. 4) is advected and at the same time has higher $\mathrm{CH}_{4}$ mixing ratios. Such air masses would be expected to occur in the tropics or subtropics. As the dynamical interpretation of the profiles is not the focus of this paper, this is not investigated further, for example, by using meteorological data.

\section{Age of air from AirCore}

The main aim of our AirCore activities is to determine mean age of air and use this to extend our long time series of mean age from balloon observations (Engel et al., 2009). The two tracers most commonly used to derive mean age are $\mathrm{CO}_{2}$ and $\mathrm{SF}_{6}$. As shown in Engel et al. (2009), the vertical gradient of mean age becomes rather small at pressures below $30 \mathrm{hPa}$

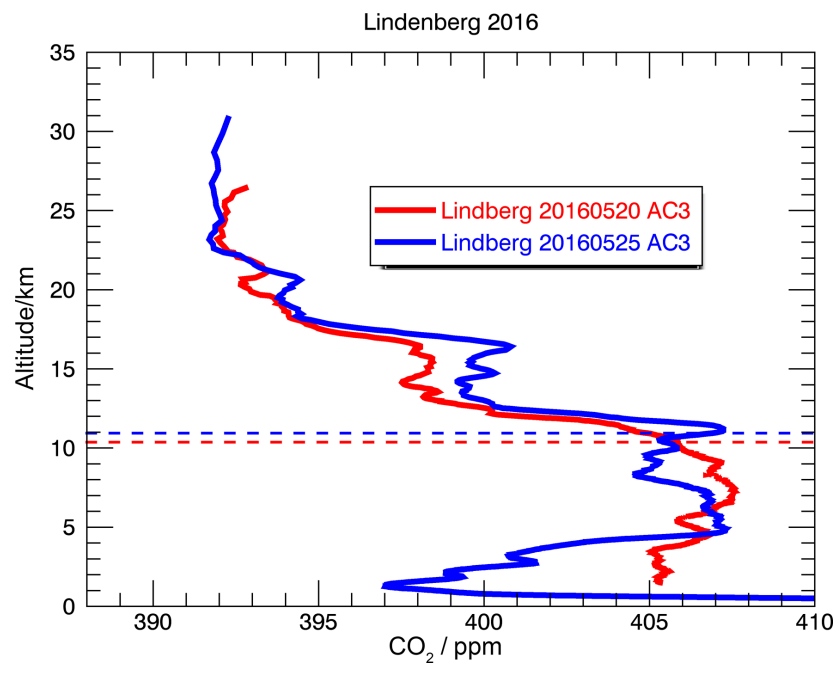

Figure 10. Vertical profiles of $\mathrm{CO}_{2}$ derived for the flights on 20 and 25 May 2016 from Lindenberg in Germany. The flight on 25 May reached higher altitudes due to a larger balloon. The dashed lines represents the thermal tropopause according to the WMO definition.

(approximately altitudes above $24 \mathrm{~km}$ ). The mean value of mean age above this altitude has been used to investigate long-term changes in mean age and in the stratospheric circulation (Engel et al., 2009). An ideal tracer for the derivations of mean age should have neither sinks nor sources in the middle atmosphere and show a monotonous, linear trend in the lower atmosphere (Hall and Plumb, 1994; Waugh and Hall, 2002). Neither $\mathrm{CO}_{2}$ nor $\mathrm{SF}_{6}$ completely fulfill these requirements (Engel et al., 2009), leading to uncertainties in the mean age values derived from observations. In the case of $\mathrm{CO}_{2}$ there are three specific issues which need to be considered: (i) the source of $\mathrm{CO}_{2}$ in the middle atmosphere due to the oxidation of $\mathrm{CH}_{4}$, (ii) the seasonal cycle of $\mathrm{CO}_{2}$ and (iii) the deviation of the deseasonalised long-term trend of $\mathrm{CO}_{2}$ in the troposphere from linearity. The procedure of calculating mean age and the question of how to take these issues into account are the same as in Engel et al. (2009) and only briefly summarised here. $\mathrm{As}^{\mathrm{CH}_{4}}$ is oxidised in the stratosphere and thus provides a source for $\mathrm{CO}_{2}$ in the stratosphere, the amount of $\mathrm{CO}_{2}$ produced from the oxidation has to be subtracted from the observed $\mathrm{CO}_{2}$ mixing ratio. The $\mathrm{CO}_{2}$ produced in the stratosphere is derived from the observed $\mathrm{CH}_{4}$ by subtracting the observed $\mathrm{CH}_{4}$ from the deseasonalised tropospheric $\mathrm{CH}_{4}$ at the time of measurement. In this procedure the fact that $\mathrm{CH}_{4}$ has a tropospheric trend and takes some time to propagate to the stratosphere is ignored. The error in mean age due to this simplification is less than half a month. $\mathrm{CO}_{2}$ has a seasonal cycle in the troposphere which can propagate into the lower stratosphere (Andrews et al., 2001a, b; Hintsa et al., 1998; Bönisch et al., 2009; Engel et al., 2006a). Rosenlof et al. (1997) found that the seasonal cycle in water vapour is observable up to potential temper- 


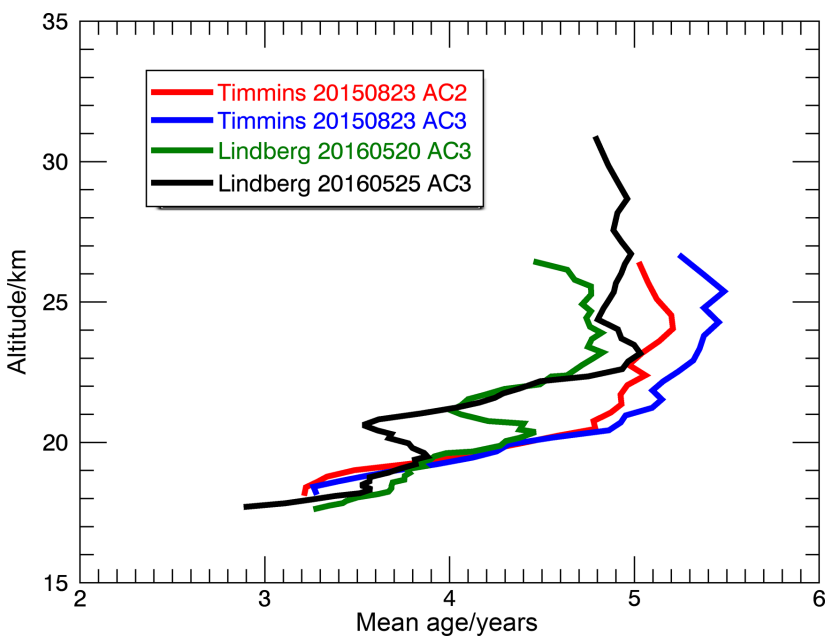

Figure 11. Vertical profiles of $\mathrm{CO}_{2}$ derived mean age for the AirCore observations by the University of Frankfurt in 2015 in Timmins, Canada and 2016 in Lindenberg, Germany.

atures of about $450 \mathrm{~K}$ and termed this region the tropically controlled transition layer. In the stratospheric overworld (above $450 \mathrm{~K}$ potential temperature) short-term influences, e.g. due to seasonal cycles in the troposphere or tropopause region are much smaller. $\mathrm{CO}_{2}$ can thus only be used as an age tracer for air at potential temperatures above $450 \mathrm{~K}$ where the mixing ratios are no longer influenced by seasonality in the troposphere. Our analysis of mean age is thus restricted to potential temperatures above $450 \mathrm{~K}$. Thirdly, the deseasonalised tropospheric trend of $\mathrm{CO}_{2}$ in the troposphere deviates from a perfect linear increase. The mean age derived from $\mathrm{CO}_{2}$ observations will thus depend on the shape of the age spectrum. To compensate for the effects of this deviation on the mean age values derived, we again followed the same approach as in Engel et al. (2009). We use a parameterisation of the width of the age spectrum $\Delta$ as function of mean age $\Gamma$ as suggested by Hall and Plumb (1994), i.e. $\frac{\Delta^{2}}{\Gamma}=0.7$ years with the general shape of the age spectrum being an inverse Gaussian function. We have further adapted the fitting period for the tropospheric trend so as to represent $98 \%$ of the air input for each individual data point (i.e. shorter time periods for the fit are applied for younger air) in order to find the best possible description of the tropospheric input time series.

The influence of all three effects on the mean age values has been included in the error analysis, again following Engel et al. (2009).

\subsection{Vertical profile observations}

Figure 11 shows the mean age profiles for the two flights from Lindenberg in May 2016 and the two AirCores flown simultaneously in August 2015 from Timmins. The data have been filtered to exclude air masses with potential temperature below $450 \mathrm{~K}$ where the $\mathrm{CO}_{2}$ seasonal cycle is still expected

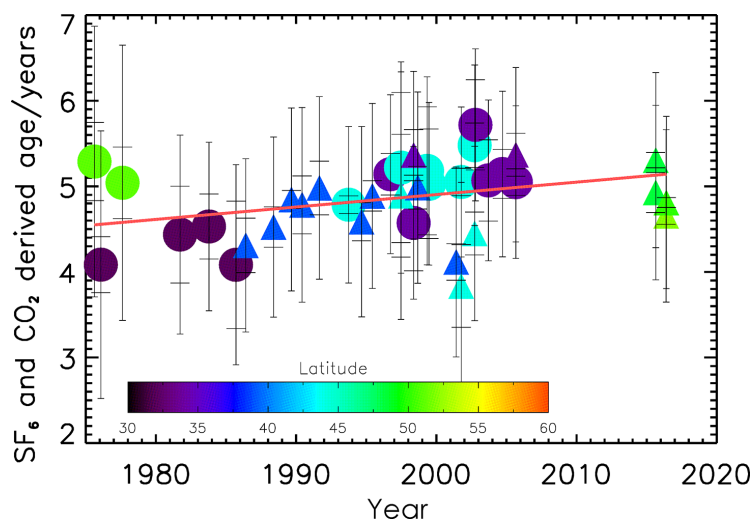

Figure 12. Time series of mean age derived from balloon observations. The data prior to 2010 are those presented in Engel et al. (2009). The data from 2015 and 2016 are derived from the AirCore measurements presented here. Each data point represents the average value of mean age derived above 30 and up to $5 \mathrm{hPa}$. The inner error bars represent the variability (error of the mean), and the larger outer error bars include the uncertainty as discussed in Engel et al. (2009). A non-significant trend of $0.15( \pm 0.18)$ years per decade is derived from these observations.

to have a significant impact. As for many other profile observations of mean age (Andrews et al., 2001a; Engel et al., 2009; Schmidt and Khedim, 1991) an increase of mean age with altitude is observed up to about $23-24 \mathrm{~km}$, above which the vertical gradient becomes very small. Mean age values above this layer are on the order of 5 years, in very good agreement with other long-term data sets. The observations from Timmins in August 2015 show slightly higher mean age values than the observations in May 2016 from Lindenberg in Germany. This could be explained by the seasonal cycle in mean age derived from MIPAS Envisat observations of $\mathrm{SF}_{6}$, showing youngest air in the Northern Hemisphere midlatitudes above $25 \mathrm{~km}$ during winter and oldest air during summer (Stiller et al., 2012). The younger spring measurements from Lindenberg could thus still be influenced from the lower mean age values during winter, while the older observations from Timmins in August 2015 should be during the maximum of the seasonal cycle. Note that the accuracy of the mean age values determined here is not limited by the analytical precision of the Picarro analyser, which is typically $0.025 \mathrm{ppm}$ - less than a week when translated into mean age.

\subsection{Extension of long-term time series}

As explained above, we want to use AirCore observations to extend our long time series of stratospheric mean age observations (Engel et al., 2009). The calculation of a temporal trend in mean age is complicated by the sparsity of the data set in combination with a vertical gradient in mean age. As the AirCore observations, in agreement with other balloon data, only show a very small vertical gradient above an altitude of $23-24 \mathrm{~km}$, corresponding to about $30 \mathrm{hPa}$, we have 
adopted the same procedure as used in Engel et al. (2009); i.e. we average all data between 30 and $5 \mathrm{hPa}$ and calculate an average value of mean age for this region of the stratosphere.

The last data point in Engel et al. (2009) was from the year 2005. There is thus a gap of 10 years between these last measurements and the new AirCore data. Overall the mean values derived from the AirCore data are in very good agreement with the values published in Engel et al. (2009). The mean values for mean age above $30 \mathrm{hPa}$ from the Timmins flights are $4.9 \pm 1$ and $5.3 \pm 1$ years, while the Lindenberg flights yield slightly lower mean age values at $4.7 \pm 1$ and $4.8 \pm 1$ years. Note that the uncertainty ranges include uncertainties in the estimated representativeness, the derivation of mean age and the observations themselves, based on the error assessment given in Engel et al. (2009). Using all the available data, we derive a new estimate of the long-term trend in mean age for the midlatitude stratosphere of the Northern Hemisphere between 30 and $5 \mathrm{hPa}$. The time period covered is now more than 40 years (1975-2016), albeit with a very restricted number of profile observations. The updated trend is now calculated to be $0.15 \pm 0.18$ years decade ${ }^{-1}$. This trend is smaller than the previous estimate $\left(0.24 \pm 0.22\right.$ years decade $\left.{ }^{-1}\right)$, but agrees within the uncertainty range. The positive trend is not significant within the $1 \sigma$ uncertainty range. Due to the reduced uncertainty of the new estimate, the largest negative trend which would be compatible with our data within the $2 \sigma$ uncertainty range remains nearly unchanged $\left(-0.21\right.$ years decade ${ }^{-1}$ instead of -0.2 years decade ${ }^{-1}$ ).

\section{Summary and conclusion}

Observations of stratospheric trace gases are well suited to investigating chemical and physical processes in the stratosphere. They are also well suited to investigate long-term changes in the stratosphere. In particular, for the investigation of long-term changes, high precision and accuracy are needed in combination with rather low costs (Müller et al., 2016; Moore et al., 2014). Most in situ measurements in the stratosphere require the use of large and expensive balloons to carry instruments above altitudes of $20 \mathrm{~km}$. The new technique of AirCore (Karion et al., 2010; Membrive et al., 2016) is ideally suited to provide such low-cost long-term observations. We have thus investigated the usefulness of AirCore for investigations of long-term evolution of mean age in order to extend the existing balloon data set used in Engel et al. (2009) and (Ray et al., 2014). The University of Frankfurt has developed an AirCore system from three different inner diameter tubes, targeted at an optimal vertical resolution in the stratosphere, while still being sufficiently lightweight to be deployed on a small balloon. During an intercomparison campaign in Timmins, Ontario in August 2015 we compared five different AirCores. We have shown that the Air-
Core technique can be used to derive high-precision vertical profiles of $\mathrm{CO}_{2}$ and $\mathrm{CH}_{4}$. Both LMD and the University of Frankfurt measurements are referenced to the same scales, but use independent calibrations. This shows that the results are also of high accuracy. For both trace gases the comparison between the different independent AirCores was better than $0.1 \%$ when vertical gradients are small, as is the case for $\mathrm{CO}_{2}$ in the midlatitude stratosphere above a pressure altitude of $30 \mathrm{hPa}$ (about $24 \mathrm{~km}$ ) and for tropospheric $\mathrm{CH}_{4}$. For $\mathrm{CH}_{4}$ in the stratosphere, where there is a large vertical gradient the typical agreement was still better than $1 \%$. The agreement between two similar AirCores which sampled in parallel was always better than the agreement between different AirCores when sampling in parallel. This shows that the geometry, the analysis system and the data retrieval of the AirCore has a significant impact. We have further performed the first observations from the midlatitude site of Lindenberg in Germany using small rubber balloons. Due to careful planning, it was possible to analyse the AirCores within $1 \mathrm{~h}$ after landing. We showed that the $\mathrm{CO}$ peak from the remaining fill gas in the AirCore can be used to derive the maximum sampling altitude. In the case of the observations from Lindenberg the maximum sampling altitudes were only slightly lower than the maximum pressure altitude of the balloon. This is a good indication that the flow restriction was rather small and that the pressure equilibrium between the tube and outside air is rather fast. This was achieved in particular due to the use of a large inner diameter tube for the main volume of the AirCore and by using a sample dryer which was optimised for minimum flow restriction. Nevertheless, the altitude attribution of the sampled air remains a difficult issue, in particular when descent rates are high. The use of balloon techniques allowing for rather slow descents should thus be considered when setting up AirCore measurement sites.

We have used the new observations to calculate mean age of stratospheric air. The results from our AirCore observations are in very good agreement with previous observations using whole air sampling techniques (Engel et al., 2009) with values ranging from 4.7 to 5.3 years of mean age above a pressure altitude of $30 \mathrm{hPa}$. We have used these data to extend our long-term time series of balloon-borne mean age observations. This time series now dates from 1975 to 2016, thus spanning a total of more than 40 years. The long-term trend of mean age in the Northern Hemisphere midlatitude stratosphere deduced from this data set is $0.15 \pm 0.18$ years decade ${ }^{-1}$. This trend is smaller than the previous estimate $(0.24 \pm 0.22)$ years decade ${ }^{-1}$ but remains well within the uncertainty limit. Based on this analysis, we thus sustain our result that no significant change in mean age of air for the midlatitude stratosphere of the Northern Hemisphere can be derived from our data set. Despite the smaller positive trend derived from this extended data set, large negative changes in mean age in this region can still be excluded, as the uncertainty on the derived trend has been reduced. A negative trend in mean age of more than -0.2 years decade ${ }^{-1}$ 
for the middle stratosphere of the Northern Hemisphere midlatitudes can still be excluded with $95 \%$ confidence.

We conclude that we have shown that AirCore measurements can be used to derive vertical profiles of $\mathrm{CO}_{2}$ and $\mathrm{CH}_{4}$, even when using small balloons. These observations are of sufficient quality to derive the mean age of air and use this to extend the currently available data set of stratospheric mean age observations. We suggest that long-term observations using AirCore from a few selected stations covering different latitude bands may provide a useful tool for investigating long-term changes in mean age. An extension of the AirCore technique to other tracers gases as suggested by Moore et al. (2014) may provide a valuable addition as these gases can also be used to study long-term changes in the stratosphere. Müller et al. (2016) suggested that a long-term network for water vapour measurements in the stratosphere should be set up to monitor this radiatively important trace gas. We suggest that such a network could be complemented by AirCore observations. Such additional AirCore observations would put the observations of changing water vapour into the general context of a changing stratospheric circulation. In addition, if both measurements are performed simultaneously, the observations of methane from the AirCore instruments and $\mathrm{H} 2 \mathrm{O}$ from the water vapour network could be used to derive the sum of $2 \times \mathrm{CH}_{4}+\mathrm{H}_{2} \mathrm{O}$, which has been identified to show much less variability in the stratosphere than $\mathrm{H}_{2} \mathrm{O}$.

Data availability. Data are available from the corresponding author upon request in NASA AMES format.

Competing interests. The authors declare that they have no conflict of interest.

Acknowledgements. The work of the University of Frankfurt on AirCore has been funded through the ROMIC programme of the German Ministry of Science and Education (Grant no. 01LG1221) and the EU Infrastructure Project RINGO (Grant agreement no. 730944). We would like to thank the French Space Agency CNES for balloon operations in Timmins and the team of Ruud Dirksen from the German Weather Service (DWD) in Lindenberg. The support of the workshops and technicians at the University of Frankfurt is gratefully acknowledged. Special thanks go to Huilin Chen from the University of Groningen in the Netherlands for many valuable discussions on AirCore techniques and an introduction to AirCore measurements during measurements from Sodankylä. Olivier Membrive was funded by EIT/Climate-KIC, a body of the European Union.

Edited by: M. von Hobe

Reviewed by: E. Ray and D. Waugh

\section{References}

Andrews, A. E., Boering, K. A., Daube, B. C., Wofsy, S. C., Loewenstein, M., Jost, H., Podolske, J. R., Webster, C. R., Herman, R. L., Scott, D. C., Flesch, G. J., Moyer, E. J., Elkins, J. W., Dutton, G. S., Hurst, D. F., Moore, F. L., Ray, E. A., Romashkin, P. A., and Strahan, S. E.: Mean ages of stratospheric air derived from in situ observations of $\mathrm{CO}_{2}, \mathrm{CH}_{4}$, and $\mathrm{N}_{2} \mathrm{O}$, J. Geophys. Res., 106, 32295-32314, https://doi.org/10.1029/2001jd000465, 2001a.

Andrews, A. E., Boering, K. A., Wofsy, S. C., Daube, B. C., Jones, D. B., Alex, S., Loewenstein, M., Podolske, J. R., and Strahan, S. E.: Empirical age spectra for the midlatitude lower stratosphere from in situ observations of $\mathrm{CO}_{2}$ : Quantitative evidence for a subtropical "barrier" to horizontal transport, J. Geophys. Res., 106, 10257-10274, 2001b.

Austin, J. and Li, F.: On the relationship between the strength of the Brewer-Dobson circulation and the age of stratospheric air, Geophys. Res. Lett., 33, L17807, https://doi.org/10.1029/2006gl026867, 2006.

Bönisch, H., Engel, A., Curtius, J., Birner, Th., and Hoor, P.: Quantifying transport into the lowermost stratosphere using simultaneous in-situ measurements of SF6 and $\mathrm{CO}_{2}$, Atmos. Chem. Phys. 9, 5905-5919, https://doi.org/10.5194/acp-9-5905-2009, 2009.

Butchart, N., Scaife, A. A., Bourqui, M., de Grandpre, J., Hare, S. H. E., Kettleborough, J., Langematz, U., Manzini, E., Sassi, F., Shibata, K., Shindell, D., and Sigmond, M.: Simulations of anthropogenic change in the strength of the Brewer-Dobson circulation, Clim. Dynam., 27, 727-741, https://doi.org/10.1007/s00382-006-0162-4, 2006.

Butchart, N.: The Brewer-Dobson circulation, Rev. Geophys., 52, 157-184, https://doi.org/10.1002/2013RG000448, 2014.

Chen, H., R. Kivi, Heikkinen, P., Kers, B., Vries, M. d., Hatakka, J., Laurila, T., Sweeney, C., and Tans, P.: High-latitude balloon observations of $\mathrm{CO}_{2} / \mathrm{CH}_{4} / \mathrm{CO}$ using AirCore: evaluation of Sodankylä TCCON retrievals, Atmos. Meas. Tech., in preperation, 2017.

Durry, G. and Hauchecorne, A.: Evidence for long-lived polar vortex air in the mid-latitude summer stratosphere from in situ laser diode $\mathrm{CH}_{4}$ and $\mathrm{H}_{2} \mathrm{O}$ measurements, Atmos. Chem. Phys., 5, 1467-1472, 10.5194/acp-5-1467-2005, 2005.

Engel, A., Bönisch, H., Brunner, D., Fischer, H., Franke, H., Günther, G., Gurk, C., Hegglin, M., Hoor, P., Königstedt, R., Krebsbach, M., Maser, R., Parchatka, U., Peter, T., Schell, D., Schiller, C., Schmidt, U., Spelten, N., Szabo, T., Weers, U., Wernli, H., Wetter, T., and Wirth, V.: Highly resolved observations of trace gases in the lowermost stratosphere and upper troposphere from the Spurt project: an overview, Atmos. Chem. Phys., 6, 283-301, https://doi.org/10.5194/acp-6-283-2006, 2006a.

Engel, A., Möbius, T., Haase, H.-P., Bönisch, H., Wetter, T., Schmidt, U., Levin, I., Reddmann, T., Oelhaf, H., Wetzel, G., Grunow, K., Huret, N., and Pirre, M.: Observation of mesospheric air inside the arctic stratospheric polar vortex in early 2003, Atmos. Chem. Phys., 6, 267-282, https://doi.org/10.5194/acp-6-267-2006, 2006b.

Engel, A., Mobius, T., Bonisch, H., Schmidt, U., Heinz, R., Levin, I., Atlas, E., Aoki, S., Nakazawa, T., Sugawara, S., Moore, F., Hurst, D., Elkins, J., Schauffler, S., Andrews, A., and Boering, K.: Age of stratospheric air unchanged within 
uncertainties over the past 30 years, Nat. Geosci., 2, 28-31, https://doi.org/10.1038/NGEO388, 2009.

Garny, H., Birner, T., Bönisch, H., and Bunzel, F.: The effects of mixing on age of air, J. Geophys. Res.-Atmos., 119, 7015-7034, https://doi.org/10.1002/2013JD021417, 2014.

Ghysels, M., Gomez, L., Cousin, J., Tran, H., Amarouche, N., Engel, A., Levin, I., and Durry, G.: Temperature dependences of air-broadening, air-narrowing and line-mixing coefficients of the methane nu(3) $\mathrm{R}(6)$ manifold lines-Application to in-situ measurements of atmospheric methane, J. Quant. Spectrosc. Ra., 133, 206-216, https://doi.org/10.1016/j.jqsrt.2013.08.003, 2014.

Haenel, F. J., Stiller, G. P., von Clarmann, T., Funke, B., Eckert, E., Glatthor, N., Grabowski, U., Kellmann, S., Kiefer, M., Linden, A., and Reddmann, T.: Reassessment of MIPAS age of air trends and variability, Atmos. Chem. Phys., 15, 13161-13176, https://doi.org/10.5194/acp-15-13161-2015, 2015.

Hall, T. M. and Plumb, R. A.: Age as a diagnostic of stratospheric transport, J. Geophys. Res., 99, 1059-1070, https://doi.org/10.1029/93jd03192, 1994.

Hintsa, E. J., Boering, K. A., Weinstock, E. M., Anderson, J. G., Gary, B. L., Pfister, L., Daube, B. C., Wofsy, S. C., Loewenstein, M., Podolske, J. R., Margitan, J. J., and Bui, T. P.: Troposphereto-stratosphere transport in the lowermost stratosphere from measurements of $\mathrm{H}_{2} \mathrm{O}, \mathrm{CO}_{2}, \mathrm{~N}_{2} \mathrm{O}$ and $\mathrm{O}_{3}$, Geophys. Res. Lett., 25, 2655-2658, 1998.

Karion, A., Sweeney, C., Tans, P., and Newberger, T.: AirCore: An Innovative Atmospheric Sampling System, J. Atmos. Ocean. Tech., 27, 1839-1853, https://doi.org/10.1175/2010JTECHA1448.1, 2010.

Kida, H.: General-Circulation of Air Parcels and Transport Characteristics Derived from a Hemispheric Gcm, 2. Very Long-Term Motions of Air Parcels in the Troposphere and Stratosphere, J. Meteorol. Soc. Jpn., 61, 510-523, 1983.

Membrive, O., Crevoisier, C., Sweeney, C., Danis, F., Hertzog, A., Engel, A., Bönisch, H., and Picon, L.: AirCore-HR: A high resolution column sampling to enhance the vertical description of $\mathrm{CH}_{4}$ and $\mathrm{CO}_{2}$, Atmos. Meas. Tech. Discuss., https://doi.org/10.5194/amt-2016-236, in review, 2016.

Moore, F. L., Ray, E. A., Rosenlof, K. H., Elkins, J. W., Tans, P., Karion, A., and Sweeney, C.: A Cost-Effective Trace Gas Measurement Program for Long-Term Monitoring of the Stratospheric Circulation, B. A. Meteorol. Soc., 95, 147-155, https://doi.org/10.1175/bams-d-12-00153.1, 2014.
Müller, R., Kunz, A., Hurst, D. F., Rolf, C., Krämer, M., and Riese, M.: The need for accurate long-term measurements of water vapor in the upper troposphere and lower stratosphere with global coverage, Earth's Future, 4, 25-32, https://doi.org/10.1002/2015EF000321, 2016.

Ploeger, F., Abalos, M., Birner, T., Konopka, P., Legras, B., Müller, R., and Riese, M.: Quantifying the effects of mixing and residual circulation on trends of stratospheric mean age of air, Geophys. Res. Lett., 42, 2047-2054, https://doi.org/10.1002/2014GL062927, 2015.

Ray, E. A., Moore, F. L., Rosenlof, K. H., Davis, S. M., Sweeney, C., Tans, P., Wang, T., Elkins, J. W., Bönisch, H., Engel, A., Sugawara, S., Nakazawa, T., and Aoki, S.: Improving stratospheric transport trend analysis based on SF6 and $\mathrm{CO}_{2}$ measurements, J. Geophys. Res.-Atmos., 119, 14110-114128, https://doi.org/10.1002/2014JD021802, 2014.

Rosenlof, K. H., Tuck, A. F., Kelly, K. K., Russell, J. M., and McCormick, M. P.: Hemispheric asymmetries in water vapor and inferences about transport in the lower stratosphere, J. Geophys. Res., 102, 13213-13234, https://doi.org/10.1029/97jd00873, 1997.

Schmidt, U. and Khedim, A.: Insitu measurements of carbondioxide in the winter arctic vortex and at midlatitudes - an indicator of the age of stratopheric air, Geophys. Res. Lett., 18, 763-766, https://doi.org/10.1029/91g100022, 1991.

Stiller, G. P., von Clarmann, T., Haenel, F., Funke, B., Glatthor, N., Grabowski, U., Kellmann, S., Kiefer, M., Linden, A., Lossow, S., and Lopez-Puertas, M.: Observed temporal evolution of global mean age of stratospheric air for the 2002 to 2010 period, Atm. Chem. Phys., 12, 3311-3331, https://doi.org/10.5194/acp12-3311-2012, 2012.

Toon, G. C., Blavier, J. F., Sen, B., Margitan, J. J., Webster, C. R., May, R. D., Fahey, D., Gao, R., Del Negro, L., Proffitt, M., Elkins, J., Romashkin, P. A., Hurst, D. F., Oltmans, S., Atlas, E., Schauffler, S., Flocke, F., Bui, T. P., Stimpfle, R. M., Bonne, G. P., Voss, P. B., and Cohen, R. C.: Comparison of MkIV balloon and ER-2 aircraft measurements of atmospheric trace gases, J. Geophys. Res.-Atmos., 104, 26779-26790, https://doi.org/10.1029/1999JD900379, 1999.

Waugh, D. W. and Hall, T. M.: Age of stratospheric air: Theory, observations, and models, Rev. Geophys., 40, 1-1-1-26, https://doi.org/10.1029/2000rg000101, 2002. 